\title{
Кислотно-основные и адсорбционные свойства пористого микродисперсного детонационного наноалмаза
}

\author{
Ланин С.Н., Рычкова С. А., Виноградов А.Е., Вирясов М.Б., \\ Власенко Е.В., Ланина К.С., Нестеренко П.Н., Хохлова Т.Д.
}

Московский государственный университет имени М.В. Ломоносова, Москва

Поступила в редакцию 22.12.2016 г.

\begin{abstract}
Исследована адсорбция ряда соединений, обладающих свойствами кислот, оснований и амфотерных соединений, на пористом микродисперсном детонационном наноалмазе (ПМДН) из водных растворов. Из анализа результатов адсорбции кислотных и основных красителей на поверхности ПМДН следует, что на поверхности сорбента имеются как основные, так и кислотные группы, с которыми способны вступать во взаимодействия молекулы органических кислот, оснований и амфотерных соединений. Обработка исходного образца кислотой или основанием приводит к уменьшению адсорбции кислотных и основных красителей, что может быть связано с удалением примесей с поверхности ПМДН, с которыми способны взаимодействовать кислотные и основные соединения.
\end{abstract}

Ключевые слова: сорбция, изотермы адсорбции, красители, пористый микродисперсный детонационный наноалмаз

\section{Acid-base and adsorption properties of the porous microdispersed detonation nanodiamond}

\author{
Lanin S.N., Rychkova S.A., Vinogradov A.E., Viryasov M.B., \\ Vlasenko E.V., Lanina K.S., Nesterenko P.N., Khokhlova T.D. \\ Lomonosov Moscow State University, Moscow
}

\begin{abstract}
It is necessary to choose the sorbent, which would provide a selective extraction and quantification of polar compounds from aqueous solutions, for the effective implementation of the method of sorption concentration. In recent years as potential adsorbents are increasingly attracting attention carbon sorbents based on detonation nanodiamond that possess a number of unique physical and chemical properties. Detonation nanodiamonds used directly in liquid chromatography impossible. Porous microdispersed detonation nanodiamonds (PMDN) are suitable for these purposes. The presence on the surface of various polar functional groups indicating that this sorbent is polar, which could promote increase the selectivity of the sorption of polar compounds. The purpose of this work was to study the physicochemical patterns of adsorption of polar sorbates having the properties of acids, bases and amphoteric compounds on porous microdispersed detonation nanodiamonds. It has been shown that treatment of PMDN with acid or base does not affect the surface area of the sorbent. Average values of specific surface area and pore diameter equal to $256 \mathrm{~m}^{2} / \mathrm{g}$ and $3.8 \mathrm{~nm}$, respectively. The amount of acidic and basic groups on the sorbent surface were determined by method of acid-base titration and Boehm titration. It is shown that the treatment of PMDN with acid or base leads to a reproducible amounts of basic and acidic groups. This may indicate that the obtained results are reliable. The data on adsorption of acidic and basic dyes on the surface of PMDN have shown that the surface of the sorbent contains both basic and acidic groups. Treatment of the initial sample with acid or base leads to a decrease of adsorption of acidic and basic dyes, which may be due to the removal of impurities from the PMDN surface.
\end{abstract}


Keywords: sorption, adsorption isotherms, dyes, porous microdispersed detonation nanodiamond

\section{Введение}

Сорбционное концентрирование веществ из растворов, содержащих различные органические соединения, является широко распространенным методом современной пробоподготовки. Однако, часто, в литературе отсутствуют результаты детального изучения адсорбционного поведения сорбатов на предлагаемых сорбентах. При этом рекомендуются только методики эксперимента или возможность выбора сорбентов под искомый набор определяемых соединений. Однако физикохимические аспекты процесса остаются недостаточно изученными. Определение закономерностей адсорбции различных веществ на границе раздела фаз является одной из актуальных задач физической химии. Исследования в этой области позволяют оптимизировать процессы сорбции, очистки, концентрирования и разделения веществ.

Для эффективного осуществления метода сорбционного концентрирования необходимо подобрать сорбент, который бы обеспечил селективное и количественное извлечение следовых количеств определенной группы соединений. Наиболее широко используемыми сорбентами на данный момент являются сорбенты октил- и октадецилсиликагели [1-4]. Однако, алкилсиликагели не всегда достаточно эффективны для концентрирования полярных органических соединений, например, фенолов (и их разделения [5]), и поэтому поиск новых адсорбентов для концентрирования остается одной из актуальных задач.

Углеродные наноматериалы представляют собой новый тип адсорбентов, обладающих механической прочностью и отсутствием усадки или набухания в органических растворителях. Поиск подходящего сорбента, характеризующегося высокой селективностью и обладающего значительной сорбционной емкостью по отношению к полярным соединениям, остается актуальной задачей и на сегодняшний день.

В последнее время в качестве потенциальных адсорбентов все чаще привлекают внимание сорбенты на основе детонационного наноалмаза (ультрадисперсного алмаза (УДА)), удельная поверхность которых достигает 300-400 м²/г [6-8]. Непосредственное использование детонационных наноалмазов в жидкостной хроматографии в качестве сорбента невозможно вследствие малого размера частиц (средний размер 4 нм). Однако, для этих целей пригодны пористые микродисперсные детонационные наноалмазы, полученные путем спекания ультрадисперсных алмазов при высоком давлении и температуре. Согласно литературным данным [6-9] наноалмаз не является чисто углеродным материалом, его частицы состоят из алмазного кристаллического ядра, внешней аморфной углеродной оболочки и слоя функциональных групп (гидроксильные, карбоксильные и др.). Таким образом, сорбенты на основе ультрадисперсного алмаза можно отнести к слабополярным адсорбентам, способным как к неспецифическим взаимодействиям, так и к специфическим $[10,11]$.

На сегодняшний день сорбенты на основе УДА нашли применение в ТФЭ [12], ГХ [13] и ВЭЖХ [14-19]. Также имеются работы, посвященные модифицированию поверхности наноалмаза, в том числе и наночастицами металлов, и изучению сорбционных свойств модифицированных материалов [20]. Настоящая работа посвящена изучению физико-химических закономерностей адсорбции полярных сорбатов, обладающих свойствами кислот, оснований и амфотерных соединений на пористом микродисперсном детонационном наноалмазе. 


\section{Эксперимент}

Низкотемпературная адсорбция/десорбция азота. Annapamyра. Удельную поверхность и распределение пор по размерам для образцов ПМДН определяли на приборе Quantachrome Autosorb 1C/MS/TPR/TPO.

Методика. Изотермы адсорбции/десорбции азота измерены при температуре жидкого азота $(77 \mathrm{~K})$ с помощью анализатора Quantachrome Autosorb 1C/MS/TPR/TPO. Образец ПМДН ( 30 мг) был кондиционирован при 473 К под вакуумом в течение 20 часов непосредственно перед измерениями. Полученные изотермы адсорбции/десорбции азота были проанализированы с применением методов БЭТ (метод Брунаура-Эммета-Теллера (BET, Brunauer-Emmett-Teller)), БДХ (метод Баррета-Джойнера-Халенды (BJH, Barret-Joyner-Halenda)) и t-методом ДеБура и Липпенса (t-plot method DeBoer-Lippens). Для анализа использовали три образца ПМДН: 1 - исходный образец (ПМДН-1), 2 - образец, обработанный $3 \cdot 10^{-3} \mathrm{M} \mathrm{H}_{3} \mathrm{PO}_{4}$ (ПМДН-2), 3 - образец, обработанный раствором $1 \cdot 10^{-5} \mathrm{M} \mathrm{NH}_{4} \mathrm{OH}$ (ПМДН-3).

Кислотно-основное титрование. Навески образца ПМДН (ООО «Алит», Киев, Украина) по 100 мг помещали в две колбы вместительностью $20 \mathrm{~cm}^{3}$ и прибавляли $10 \mathrm{~cm}^{3} \mathrm{HCl} 0.01 \mathrm{M}$ в первую и $10 \mathrm{~cm}^{3} \mathrm{KOH} 0.0112 \mathrm{M}$ во вторую. Колбы оставляли при комнатной температуре на сутки до установления равновесия. После установления равновесия отбирали аликвоту равновесного раствора и определяли концентрацию кислоты (титрованием водным раствором $0.0112 \mathrm{M} \mathrm{KOH} \mathrm{в} \mathrm{присутствии} \mathrm{метилового}$ оранжевого до перехода окраски из красной в жёлтую) или щелочи (титрованием водным раствором $0.01 \mathrm{M} \mathrm{HCl}$ в присутствии фенолфталеина до исчезновения малиновой окраски). После каждой серии анализа образцы ПМДН промывали водой до нейтрального $\mathrm{pH}$ и сушили при $120^{\circ} \mathrm{C}$.

Титрование по методу Боэма. В две конические колбы емкостью $20 \mathrm{~cm}^{3}$ помещали навески 0.1 г образца ПМДН. К навескам приливали 10 мл 0.011 М соответствующего раствора: раствор гидрокарбоната натрия - для определения карбоксильных групп; раствор карбоната натрия - для определения суммы карбоксильных и лактонных групп. Смесь встряхивали, оставляли на сутки до установления равновесия при комнатной температуре. Из равновесных растворов отбирали по три пробы по $3 \mathrm{~cm}^{3}$, переносили в конические колбы емкостью $20 \mathrm{~cm}^{3}$ и титровали $0.01 \mathrm{M} \mathrm{рас-}$ твором $\mathrm{HCl}$. Определяли количество $\mathrm{HCl}$, пошедшей на титрование, как среднее из трех испытаний. В качестве индикатора использовали метиловый оранжевый.

Изучение адсорбционных свойств наноалмаза в статическом режиме. Annapamypa. Определение концентрации красителей по оптической плотности их растворов проводили на спектрофотометре КФК3 (0100300) в видимой области спектра.

Реактивы и растворители. Для исследования адсорбционных свойств ПМДН использовали водные растворы трех красителей, обладающих свойствами кислот или оснований: метиленовый голубой (МГ) (рис. 1), кислотный синий антрахиноновый (КСА) (рис. 2) и кислотный оранжевый (КО) (рис. 3). Также исследовали адсорбционные свойства ПМДН по отношению к кислотно-основному индикатору метиловому оранжевому (МО), обладающего амфотерными свойствами (рис. 4).<smiles></smiles>

Рис. 1. Метиленовый голубой.<smiles>NC1=CC(S(=O)(=O)O)=C(O)C2C(=O)c3c(N)ccc(O)c3C(=O)C12</smiles>

Рис. 2. Кислотный синий 
<smiles>CS(=O)(=O)c1ccc(N=Nc2c(O)ccc3ccccc23)cc1</smiles>

Рис. 3. Кислотный оранжевый.

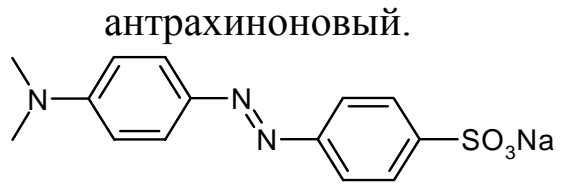

Рис. 4. Метиловый оранжевый.

Методика изучения адсорбиии красителей. Навеску 5 г ПМДН адсорбента в $5 \mathrm{~cm}^{3}$ раствора красителя с концентрацией 20 мг/дм ${ }^{3}$ встряхивали и оставляли на время, требуемое для установления адсорбционного равновесия (2-3 дня), когда концентрация раствора сорбата переставала изменяться. Определяли количество красителя, оставшегося неадсорбированным. При этом измеряли адсорбцию каждого красителя на трех образцах ПМДН: 1 - исходный образец (ПМДН-1), 2 - образец, обработанный $3 \cdot 10^{-3} \mathrm{M} \mathrm{H}_{3} \mathrm{PO}_{4}$ (ПМДН-2), 3 - образец, обработанный раствором $1 \cdot 10^{-5} \mathrm{M} \mathrm{NH}_{4} \mathrm{OH}$ (ПМДН-3).

Равновесную концентрацию красителей в растворах измеряли на спектрофотометре КФК3 (0100300) по оптической плотности при длине волны 660 нм для метиленового голубого, при 580 нм для антрахинонового синего, при 430 нм для кислотного оранжевого и при 500 нм для метилового оранжевого.

Расчетные формульы. Равновесную концентрацию красителя $C_{e}$ определяли по уравнению [21]:

$$
C_{e}=\frac{A_{e}}{A_{0}} \cdot C_{0}
$$

где $C_{0}$ - исходная концентрация красителя, моль/дм ${ }^{3} ; A_{e}$ - оптическая плотность равновесного раствора, $A_{0}$ - оптическая плотность исходного раствора.

Избыточная гиббсовская адсорбция $\Gamma_{i}$ (моль/г) при этом составляла [11]:

$$
\Gamma_{i}=\frac{\left(C_{0}-C_{e}\right) \cdot V}{m}
$$

где $V$ - объем раствора, дм ${ }^{3} ; m$ - масса сухого сорбента, г; $C_{e}-$ концентрация вещества в равновесном растворе, моль/дм ${ }^{3} ; C_{0}$ - исходная концентрация вещества, моль/дм .

Константы уравнения типа уравнения Ленгмюра рассчитывали по формуле:

$$
a=\frac{a_{m} \cdot K_{L} \cdot C_{e}}{1+K_{L} \cdot C_{e}}
$$

где $a$ и $a_{m}$ - количества адсорбированного вещества на 1 г сорбента при равновесии и адсорбционная ёмкость монослоя при насыщении, моль/г, $C_{e}-$ равновесная концентрация раствора сорбата, моль/дм ${ }^{3}, K_{L}$ - константа равновесия уравнения типа Ленгмюра, учитывающая все взаимодействия в растворе, дм ${ }^{3} /$ моль.

Линейная форма уравнения Ленгмюра:

$$
\frac{C_{e}}{a}=\frac{1}{K_{L} \cdot a_{m}}+\frac{C_{e}}{a_{m}}
$$

Параметры уравнения типа уравнения Фрейндлиха рассчитывали по формуле:

$$
a=K_{F} \cdot C_{e}^{1 / n}
$$

где $K_{F}$ - константа равновесия уравнения типа Фрейндлиха, учитывающий все взаимодействия в растворе, дм ${ }^{31 / n}$ моль ${ }^{1-1 / n} \Gamma^{-1}, 1 / n$ - параметр, указывающий на интенсивность взаимодействия адсорбент - адсорбат.

Линейная форма уравнения Фрейндлиха: 


$$
\ln a=\ln K_{F}+\frac{1}{n} \ln C_{e},
$$

позволяющая рассчитать значения констант этого уравнения

\section{Обсуждение результатов}

Изучение пористой структуры и удельной поверхности пористого микродисперсного детонационного наноалмаза методом низкотемпературной адсорбции/десорбции азота. Измеренные зависимости объёма адсорбированного и десорбированного азота от относительного давления представлены на рис. 5.

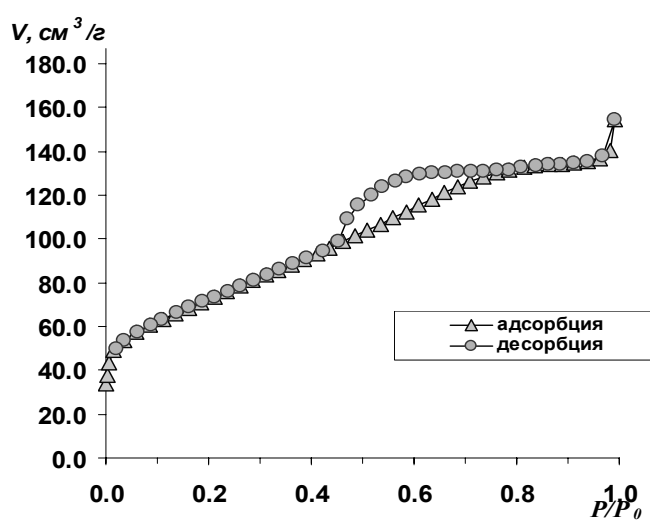

Рис. 5. Изотерма низкотемпературной ( $\mathrm{T}=77$ К) адсорбции и десорбции азота на поверхности ПМДН-1

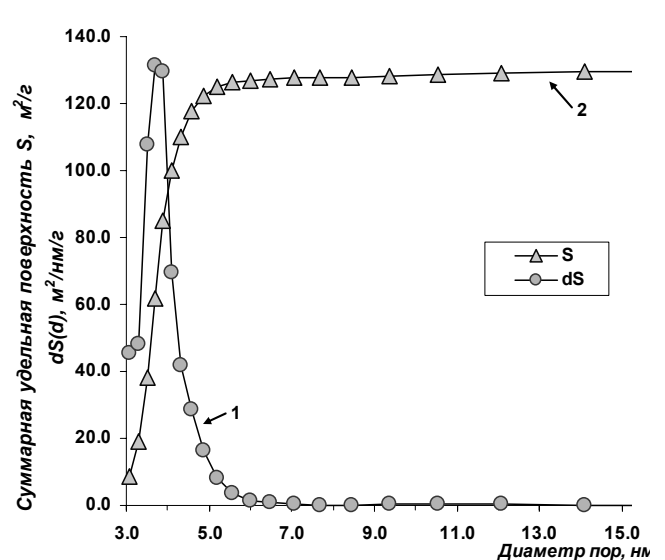

Рис. 6. Дифференциальная (1) и интегральная (2) кривые распределения пор по размерам для исследованного исходного образца ПМДН-1.

Для исследованного образца ПМДН-1 изотерма низкотемпературной адсорбции азота соответствует IV типу по классификации IUPAC (типична для мезопористых материалов) [22]. Наличие петли гистерезиса свидетельствует о капиллярной конденсации азота в объеме пор адсорбента, что указывает на наличие мезопор. Вертикальный загиб изотермы вблизи относительного давления $P / P_{0}=1$ указывает на наличие макропор в образце ПМДН-1 [22].

Размеры пор исследуемого образца ПМДН-1 можно оценить по кривым распределения пор по размерам. На рис. 6 приведены дифференциальная (кривая 1) и интегральная (кривая 2) зависимости распределения пор по размерам для исследованного образца ПМДН-1. По максимуму на дифференциальной кривой зависимости распределения пор по размерам можно судить о преобладании в образце пор со средним диаметром 3.9 нм.

В табл. 1 приведены структурные параметры исходного и обработанных кислотой или основанием образцов ПМДН, рассчитанные разными методами: БЭТ (метод Брунаура-Эммета-Теллера (BET, Brunauer-Emmett-Teller)), БДХ (метод Баррета-Джойнера-Халенды (BJH, Barret-JoynerHalenda)) и t-методом ДеБура и Липпенca (t-plot method DeBoer-Lippens).

Из табл. 1 следует, что обработка ПМДН кислотой или основанием не влияет на величину удельной поверхности исследованных образцов сорбента.

Таким образом, для исследованных образцов ПМДН средние значения удельной поверхности и диаметра пор равнялись $256 \mathrm{~m}^{2} / \Gamma$ и 3.8 нм, соответственно. 
Таблица 1. Результаты обработки данных, полученных методом низкотемпературной адсорбции/десорбции азота, разными методами.

\begin{tabular}{|c|c|c|c|}
\hline \multirow{2}{*}{ Характеристика } & \multicolumn{3}{|c|}{ Образец } \\
\cline { 2 - 4 } & ПМДН-1 & ПМДН-2 & ПМДН-3 \\
\hline Общий объём пор & $0.24 \mathrm{~cm}^{3} / \Gamma$ & $0.24 \mathrm{~cm}^{3} / \Gamma$ & $0.25 \mathrm{~cm}^{3} / \Gamma$ \\
\hline Удельная поверхность, $S_{B E T}$ & $258 \mathrm{~m}^{2} / \Gamma$ & $251 \mathrm{~m}^{2} / \Gamma$ & $259 \mathrm{~m}^{2} / \Gamma$ \\
\hline Диаметр пор $1, \mathrm{~d}_{\mathrm{BJH}}$ & $3.9 \mathrm{HM}$ & $3.7 \mathrm{HM}$ & $3.7 \mathrm{HM}$ \\
\hline
\end{tabular}

диаметры мезопор рассчитаны по десорбционной ветви изотермы

Кислотно-основное титрование поверхности наноалмаза. Анионообменная емкость ПМДН. Известно, что поверхность ПМДН содержит ряд функциональных групп кислотного и основного характера. Определение количества кислотных и основных групп проводили с использованием титриметрического метода анализа. В табл. 2 приведены результаты титрования кислотных (раствором $\mathrm{KOH}, C=0.0112 \mathrm{M}$ ) и основных групп (раствором $\mathrm{HCl}, C=0.01 \mathrm{M}$ ). По результатам анализа было установлено, что количество кислотных и основных групп на поверхности исходных образцов составляет 1.23 и 0.15 групп/нм², соответственно. Обработка образцов кислотой или основанием, а также последовательная обработка кислотой и основанием приводит к изменению количества определяемых групп на поверхности, а именно 0.53 и 0.78 групп/нм² кислотных и основных групп, соответственно. Следует отметить, что авторами [23] аналогичным образом было определено количество кислотных групп на поверхности детонационного наноалмаза, которое составило 0.47 групп/нм². Эти результаты близки к значениям, полученным в данной работе.

Таблица 2. Результаты кислотно-основного титрования образцов ПМДН.

\begin{tabular}{|c|c|c|c|}
\hline Образец & $\begin{array}{c}\mathrm{N}_{\mathrm{or}} \\
\text { групп/нм}{ }^{2}\end{array}$ & $\begin{array}{c}\mathrm{N}_{\mathrm{kr}}, \\
\text { групп/нм}{ }^{2}\end{array}$ & $\begin{array}{c}\mathrm{N}_{\Sigma} \\
\text { групп/нм}\end{array}$ \\
\hline Исходный образец (ПМДН-1) & 0.15 & 1.23 & 1,38 \\
\hline Обработанный кислотой (ПМДН-2) & 0.78 & 0.53 & 1,31 \\
\hline Обработанный основанием (ПМДН-3) & 0.78 & 0.53 & 1,31 \\
\hline $\begin{array}{c}\text { Обработанный последовательно кислотой, а затем } \\
\text { основанием (ПМДН-3') }\end{array}$ & 0.79 & 0.51 & 1,30 \\
\hline $\begin{array}{l}\text { Обработанный последовательно основанием, а за- } \\
\text { тем кислотой (ПМДН-2)' }\end{array}$ & 0.78 & 0.51 & 1,29 \\
\hline
\end{tabular}

$\mathrm{N}_{\text {ог }}$ - количество основных групп; $\mathrm{N}_{\text {кг }}$ количество кислотных групп; $\mathrm{N}_{\Sigma}$ - суммарное количество групп

Из данных табл. 2 следует, что обработка образца ПМДН кислотой или основанием, а также последовательная обработка кислотой и основанием приводит к получению воспроизводимых значений количества основных и кислотных групп. Это может свидетельствовать о достоверности полученных результатов [24] и стабилизации поверхностных свойств ПМДН.

Титрование поверхности наноалмаза методом Боэма. Для определения количества функциональных групп различной кислотности (гидроксильных, лактонных и карбоксильных групп) на поверхности ПМДН использовали широко используемый метод Боэма [23]. Результаты приведены в табл. 3. Авторами работы [23] также был применен метод титрования по Боэму для определения количества функциональных групп различной кислотности на поверхности детонационного наноалмаза и соотношение карбоксильных и лактонных групп составило 1:1. Эти значения достаточно хорошо согласуются с полученными результатами в данной работе (табл. 3). 
Таблица 3. Количество различных кислотных групп на поверхности ПМДН-2' (ПМДН-3’), определенных по методу Боэма.

\begin{tabular}{|c|c|}
\hline Группы & Количество, групп/нм ${ }^{2}$ \\
\hline Карбоксильные группы & 0.10 \\
\hline Лактонные группы & 0.08 \\
\hline Гидроксильные группы & 0.34 \\
\hline
\end{tabular}

По результатам титрования по методу Боэма можно судить о присутствии на поверхности исследуемого ПМДН функциональных групп различной кислотности. Следовательно, изменение $\mathrm{pH}$ раствора может привести к диссоциации разных кислотных функциональных групп на поверхности сорбента, что, в свою очередь, может и должно отразиться на адсорбционных свойствах образцов ПМДН.

Адсорбция красителей на поверхности ПМДН. Еще одним методом, позволяющим оценить кислотно-основные свойства ПМДН, является адсорбция красителей и индикаторов, обладающих основными или кислотными свойствами.

На рис. 7 приведены начальные участки изотерм адсорбции красителя кислотного синего антрахинонового (КСА). Высокие значения адсорбции (0.46 ммоль/г) красителя КСА на поверхности ПМДН-1 соответствуют количеству

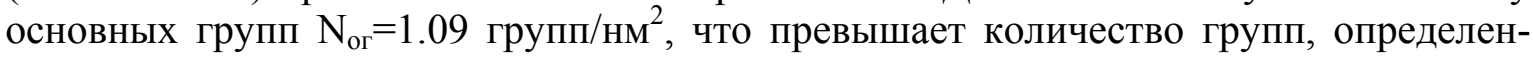
ных методом кислотно-основного титрования (табл. 2).

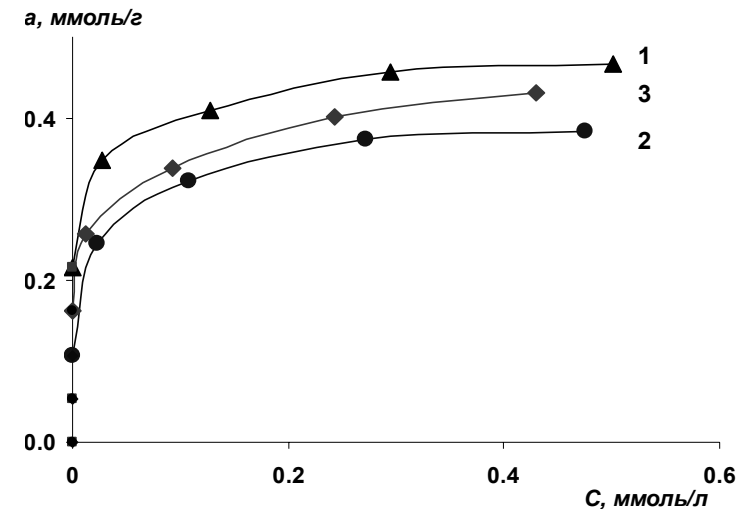

Рис. 7. Изотермы адсорбции кислотного синего антрахинонового на образцах ПМДН: 1 - исходный образец (ПМДН-1); 2 - образец, обработанный фосфорной кислотой $3 \cdot 10^{-3}$ М (ПМДН-2), 3 - образец, обработанный гидроксидом аммония $1 \cdot 10^{-5}$ М (ПМДН-3).

Однако известно, что данный краситель способен образовывать комплексы с примесями металлов, в частности, алюминия (рис. 8). Из рис. 7 видно, что КСА сорбируется сильнее на исходном образце (рис. 7 (1)), на обработанных образцах (рис. 7, (2) и (3)) адсорбция этого красителя уменьшается. Это может быть связано с адсорбцией КСА на поверхности ПМДН-1 за счет комплексообразования с примесями металлов.<smiles>CC(C)(C)Oc1ccc(N)c2c1C(=O)c1c(N)cc([N+](=O)[O-])c(O)c1C2=O</smiles>

Рис. 8. Комплекс, образованный примесями алюминия с КСА. 
Полученные изотермы адсорбции были проанализированы с применением уравнений типа Ленгмюра и Фрейндлиха. Линеаризованные изотермы адсорбции КСА на поверхности ПМДН представлены на рис. 9 а и б.

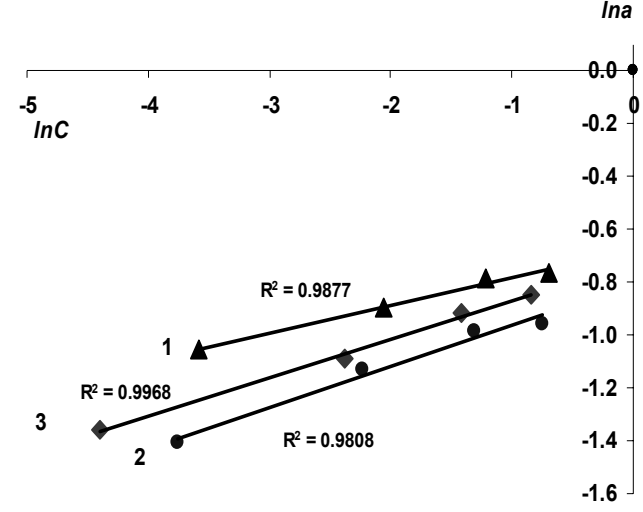

a

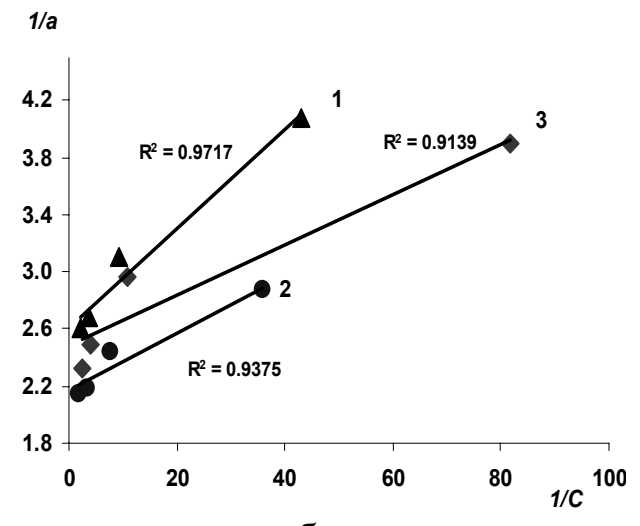

6

Рис. 9. Линейные формы изотерм адсорбции КСА в координатах Фрейндлиха (а) и Ленгмюра (б), адсорбированного на поверхности образцов ПМДН: 1 - исходный образец (ПМДН-1); 2 - образец, обработанный фосфорной кислотой $3 \cdot 10^{-3} \mathrm{M}$ (ПМДН-2), 3 - образец, обработанный гидроксидом аммония $1 \cdot 10^{-5} \mathrm{M}($ ПМДН-3).

Рассчитанные значения констант уравнений Ленгмюра и Фрейндлиха для изотерм адсорбции КСА на трех образцах ПМДН приведены в табл. 4. Из сравнения коэффициентов детерминации следует, что линейные уравнения, полученные по модели Фрейндлиха, характеризуются более высокими значениями $\mathrm{R}^{2}$. Уравнение изотермы модели Фрейндлиха используется для описания адсорбции на неоднородных поверхностях. Так как адсорбционные центры по этой модели обладают различными величинами энергии, то в первую очередь происходит заполнение наиболее активных сорбционных центров с максимальной энергией сорбции [25].

Применимость модели Фрейндлиха к описанию адсорбции КСА может свидетельствовать о неоднородности поверхности сорбента, что, возможно, вызвано адсорбцией данного красителя за счет образования комплексов КСА с примесями металлов на поверхности ПМДН. Вероятно, примеси металлов на поверхности ПМДН распределены неравномерно, поэтому и возникает неоднородность в величинах энергии адсорбции на активных центрах поверхности.

Из данных табл. 4 следует, что константа уравнения Фрейндлиха $K_{F}$ максимальна для образца ПМДН-1 и минимальна для образца ПМДН-2. Обработка ортофосфорной кислотой образца ПМДН приводит к уменьшению взаимодействия молекул КСА с поверхностью сорбента. Для образцов ПМДН-3 и ПМДН-1 величины $K_{F}$ сопоставимы. Это может быть связано с тем, что на исходном образце (как и в случае ПМДН-3) кислотные группы, вероятно, находились в катионной форме, что способствовало увеличению адсорбции кислотного красителя на поверхности ПМДН-1 за счет снижения общей электроотрицательности поверхности. Обработка кислотой приводит к переводу катионных групп в Н-форму и адсорбция КСА уменьшается в 1.2 раза (для ПМДН-1 $a_{m}=0.46$ ммоль/г, для ПМДН-2 $a_{m}=0.38$ ммоль $/ г$ ).

Для сравнения нами была измерена адсорбция на трех образцах ПМДН кислотного красителя кислотного оранжевого (КО), не способного к комплексообразованию. Изотермы адсорбции красителя КО представлены на рис. 10.

Из рис. 10 следует, что адсорбция КО в несколько раз ниже, чем адсорбция КСА. Из сравнения площадок, занимаемых одной молекулой сорбата в монослое, полученных для этих двух красителей, следует, что $\omega_{\text {ксА }}<\omega_{\kappa о}$. Это может быть свя- 
зано с тем, что молекула КО является более вытянутой, чем молекула КСА и вследствие своей гибкой структуры взаимодействует с поверхностью сорбента сразу несколькими группами. Такая ориентация молекулы приводит к экранированию соседних групп поверхности сорбента, с которыми могли бы взаимодействовать другие молекулы сорбата. И это приводит к уменьшению адсорбции данного красителя на поверхности ПМДН.

Таблица 4. Параметры уравнений моделей Ленгмюра и Фрейндлиха для изотерм адсорбции КСА на ПМДН и рассчитанные из модели Ленгмюра площадки, занимаемые одной молекулой в монослое.

\begin{tabular}{|c|c|c|c|}
\hline \multirow{2}{*}{ Параметры модели } & \multicolumn{3}{|c|}{ Образец } \\
\hline & ПМДН-1 & ПМДН-2 & ПМДН-3 \\
\hline \multicolumn{4}{|c|}{ Модель Ленгмюра } \\
\hline$a_{m,}$ Ммоль $/ \Gamma$ & 0.46 & 0.38 & 0.40 \\
\hline$K_{L, \text { л/ммоль }}$ & 107 & 75 & 140 \\
\hline $\mathrm{R}^{2^{*}}$ & 0.937 & 0.972 & 0.914 \\
\hline \multicolumn{4}{|c|}{ Модель Фрейндлиха } \\
\hline $1 / \mathrm{n}$ & 0.11 & 0.15 & 0.15 \\
\hline$K_{F}$, л $^{1 / \mathrm{n}} \bullet$ моль ${ }^{1-1 / \mathrm{n}} / \Gamma$ & 0.51 & 0.44 & 0.49 \\
\hline $\mathrm{R}^{2}$ & 0.988 & 0.981 & 0.997 \\
\hline \multicolumn{4}{|c|}{ Площадка, занимаемая одной молекулой $\omega$, нм$^{2}$} \\
\hline & 0.93 & 1.12 & 1.06 \\
\hline
\end{tabular}

$\mathrm{R}^{2}$ - коэффициент детерминации

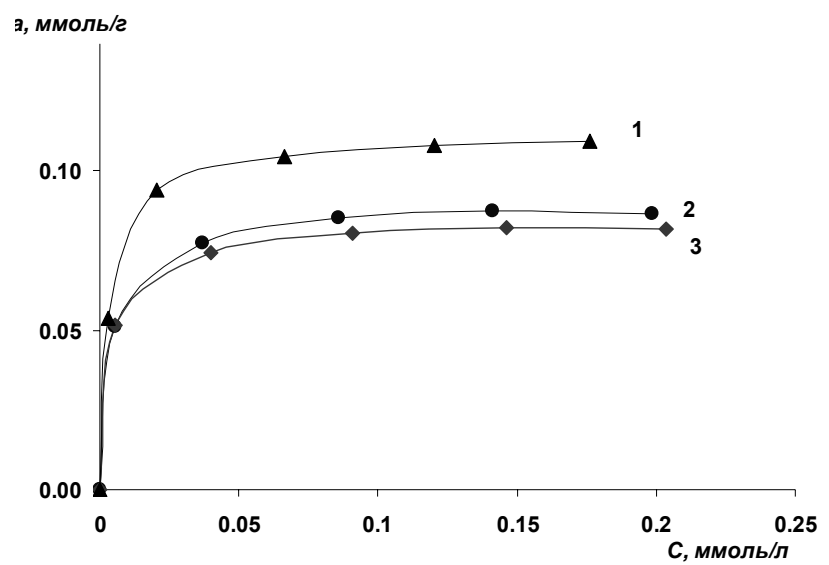

Рис. 10. Изотермы адсорбции красителя кислотного оранжевого на образцах ПМДН: 1 - исходный образец (ПМДН-1); 2 - образец, обработанный фосфорной кислотой $3 \cdot 10^{-3} \mathrm{M}$ (ПМДН-2), 3 - образец, обработанный гидроксидом аммония $1 \cdot 10^{-5}$ М (ПМДН-3).

Аналогичным образом, как и в случае КСА, измеренные изотермы адсорбции были проанализированы с применением моделей Фрейндлиха и Ленгмюра (рис. 11 (a и б), табл. 5).

В отличие от адсорбции КСА для описания адсорбции КО лучше подходит модель Ленгмюра $\left(\mathrm{R}^{2}=0.995-0.999\right)$. Применимость модели Ленгмюра в данном случае указывает на адсорбцию на активных центрах с одинаковой энергией.

Как и в случае КСА, кислотный оранжевый сильнее адсорбируется на исходном образце и слабее на обработанных кислотой или основанием. 


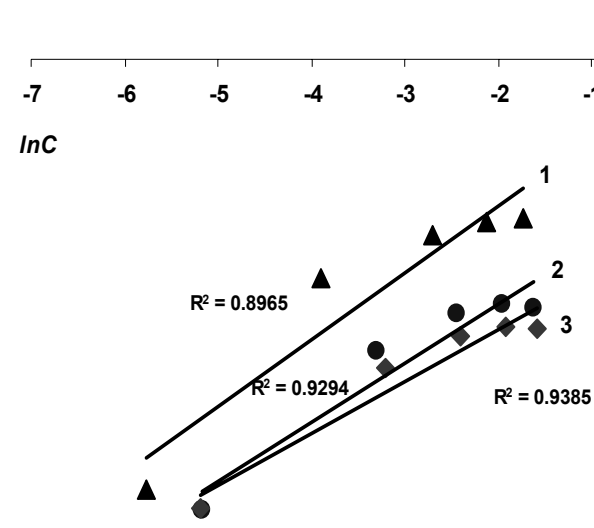

a

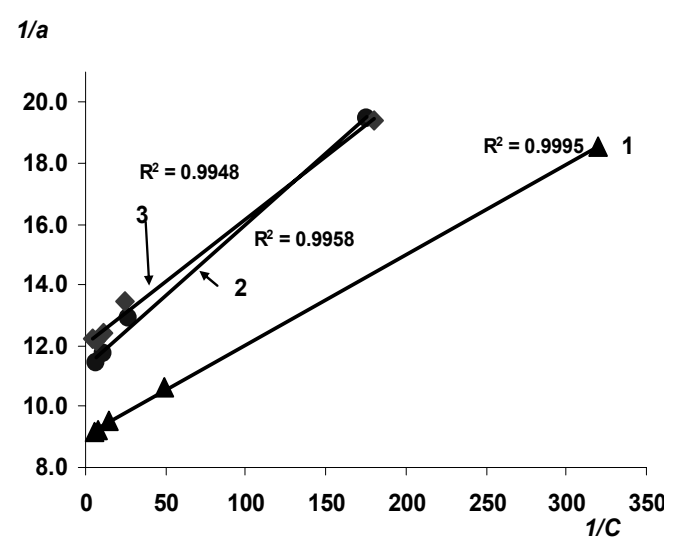

6

Рис. 11. Линейные формы изотерм адсорбции КО в координатах Фрейндлиха

(а) и Ленгмюра (б), адсорбированного на поверхности образцов ПМДН:

1 - исходный образец (ПМДН-1); 2 - образец, обработанный фосфорной кислотой $3 \cdot 10^{-3} \mathrm{M}$ (ПМДН-2), 3 - образец, обработанный гидроксидом аммония $1 \cdot 10^{-5} \mathrm{M}$

(ПМДН-3)

Таблица 5. Параметры моделей Фрейндлиха и Ленгмюра для изотерм адсорбции КО на образцах ПМДН и рассчитанные из модели Ленгмюра площадки, занимаемые одной молекулой в монослое.

\begin{tabular}{|c|c|c|c|}
\hline \multirow{2}{*}{ Параметры модели } & \multicolumn{3}{|c|}{ Образец } \\
\hline & ПМДН-1 & ПМДН-2 & ПМДН-3 \\
\hline \multicolumn{4}{|c|}{ Модель Ленгмюра } \\
\hline$a_{m, \text { Ммоль/Г }}$ & 0.110 & 0.088 & 0.083 \\
\hline 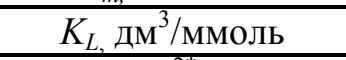 & 305 & 242 & 293 \\
\hline $\mathrm{R}^{2^{*}}$ & 0.999 & 0.996 & 0.995 \\
\hline \multicolumn{4}{|c|}{ Модель Фрейндлиха } \\
\hline $1 / \mathrm{n}$ & 0.17 & 0.15 & 0.13 \\
\hline$K_{F,}$ дм $^{31 / \mathrm{n}} \bullet$ моль $^{1-1 / \mathrm{n}} / \Gamma$ & 0.160 & 0.119 & 0.107 \\
\hline $\mathrm{R}^{2^{*}}$ & 0.896 & 0.929 & 0.938 \\
\hline \multicolumn{4}{|c|}{ Площадка, занимаемая одной молекулой $\omega$, нм $^{2}$} \\
\hline & 3.88 & 4.84 & 5.17 \\
\hline
\end{tabular}

${ }^{*} \mathrm{R}^{2}$ - коэффициент детерминации

Из данных табл. 5 следует, что константа уравнения Ленгмюра $K_{L}$ максимальна для образца ПМДН-1 и минимальна для образца ПМДН-2. Обработка образца ПМДН гидроксидом аммония также приводит к уменьшению взаимодействия молекул КО с поверхностью сорбента. Однако, в данном случае значения констант уравнения Ленгмюра $K_{L}$, полученные для образцов ПМДН-1 и ПМДН-3, близки. Величины емкости монослоя $a_{m}$ КО на ПМДН-2 и ПМДН-3 сопоставимы (для ПМДН-2 $a_{m}=0.088$ ммоль $/ г$, для ПМДН-3 $a_{m}=0.083$ ммоль $\left./ г\right)$.

В качестве еще одного тестового сорбата использовали кислотно-основной индикатор - метиловый оранжевый (МO). Структурная формула этого органического соединения очень схожа со структурной формулой кислотного оранжевого (рис. 3 и 4, соответственно). Оба соединения принадлежат к классу азосоединений (производные азобензола). Отличием является наличие структурного фрагмента основного $N, N$-диметиланилина в молекуле МО, вместо кислотного фрагмента $\beta$-нафтола в молекуле КО. МО является амфотерным соединением и способен вступать во взаимодействия как с основными, так и с кислотными группами на поверхности сорбента. 
Изотермы адсорбции МО приведены на рис. 12 для трех образцов: ПМДН-1, ПМДН2 и ПМДН-3.

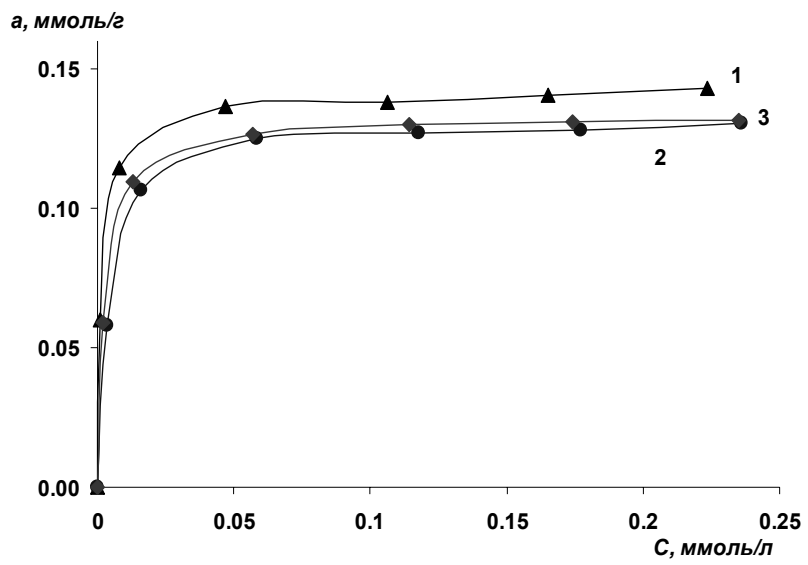

Рис. 12. Изотермы адсорбции кислотно-основного индикатора метилового оранжевого на образцах ПМДН: 1 - исходный образец (ПМДН-1); 2 - образец, обработанный фосфорной кислотой $3 \cdot 10^{-3} \mathrm{M}$ (ПМДН-2), 3 - образец, обработанный гидроксидом аммония $1 \cdot 10^{-5} \mathrm{M}($ (ПДН-3)

Из рис. 13 следует, что величина адсорбции метилового оранжевого выше, чем сорбция кислотного оранжевого. Вероятно, это связано с присутствием основной группы в молекуле МО, которая способна вступать во взаимодействия с кислотными центрами на поверхности ПМДН.

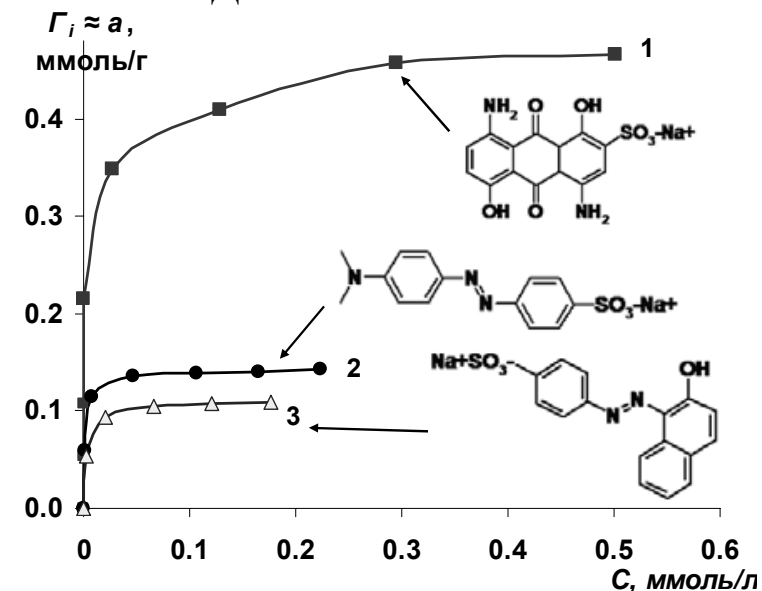

Рис. 13. Изотермы адсорбции красителей на исходном образце ПМДН-1: 1 - кислотный синий антрахиноновый (КСА); 2 - метиловый оранжевый (МО), 3 - кислотный оранжевый (КО).

Однако адсорбция МО на ПМДН-1 ниже, чем определенная для КСА. Это опять же может быть связано со строением молекулы МО, как и в случае схожей структуры КО. При этом площадка, занимаемая одной молекулой МО в монослое, возрастает при обработке сорбента кислотой и основанием, как и в случае КО.

Вероятно, обработка ПМДН кислотой и основанием приводит к возникновению избыточного заряда на поверхности сорбента (диссоциированию или протонированию кислотных и основных групп на поверхности образца), что несколько изменяет ориентацию КО и МО. При этом для молекул МО наблюдается большее сродство к поверхности образцов ПМДН, чем для КО.

Полученные изотермы адсорбции МО на трех образцах ПМДН были проанализированы с использованием моделей Ленгмюра и Фрейндлиха (рис. 14 (а и б), 
табл. 6). В табл. 6 приведены значения констант и коэффициентов детерминации уравнений, полученных для данных моделей сорбции.

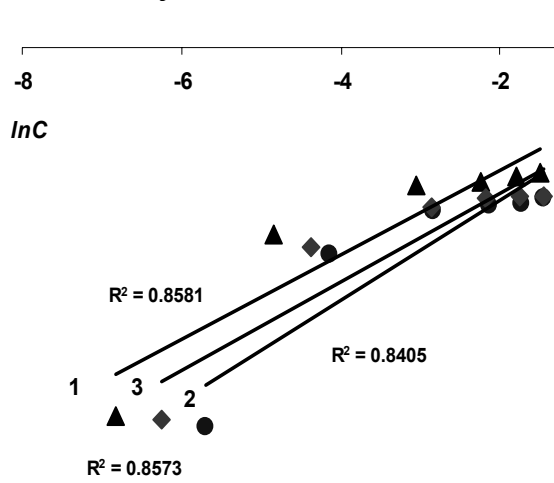

a

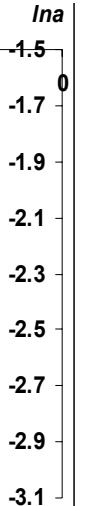

$-3.1$

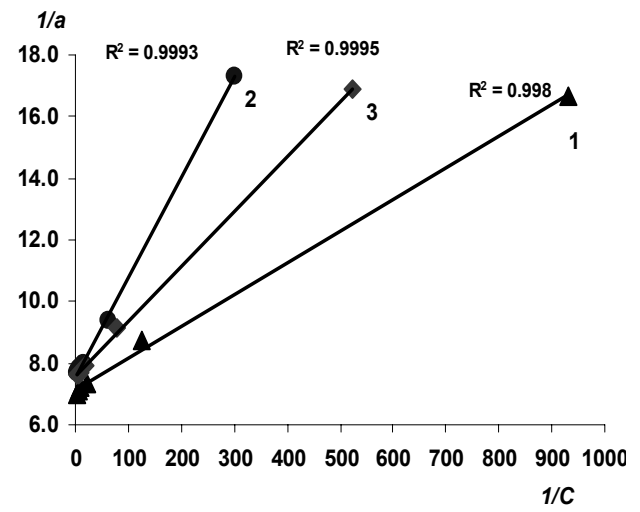

6

Рис.14. Линейные формы изотерм адсорбции МО в координатах Фрейндлиха (а) и Ленгмюра (б), адсорбированного на поверхности образцов ПМДН: 1 - исходный образец (ПМДН-1); 2 - образец, обработанный фосфорной кислотой $3 \cdot 10^{-3} \mathrm{M}$ (ПМДН-2), 3 - образец, обработанный гидроксидом аммония $1 \cdot 10^{-5} \mathrm{M}$ (ПМДН-3)

Таблица 6. Параметры моделей Ленгмюра и Фрейндлиха для изотерм адсорбции МО на ПМДН и рассчитанные из модели Ленгмюра площадки, занимаемые одной молекулой в монослое.

\begin{tabular}{|c|c|c|c|}
\hline \multirow{2}{*}{ Параметры модели } & \multicolumn{3}{|c|}{ Образец } \\
\hline & ПМДН-1 & ПМДН-2 & ПМДН-3 \\
\hline \multicolumn{4}{|c|}{ Модель Ленгмюра } \\
\hline$a_{m}$ Ммоль/г & 0.14 & 0.13 & 0.13 \\
\hline$K_{L, ~}$ дм³/ммоль & 694 & 231 & 424 \\
\hline $\mathrm{R}^{2^{*}}$ & 0.998 & 0.999 & 0.999 \\
\hline \multicolumn{4}{|c|}{ Модель Фрейндлиха } \\
\hline $1 / \mathrm{n}$ & 0.15 & 0.18 & 0.16 \\
\hline$K_{F}$ дм $^{31 / n} \cdot$ моль $^{1-1 / \mathrm{n}} / \Gamma$ & 0.19 & 0.18 & 0.18 \\
\hline $\mathrm{R}^{2}$ & 0.858 & 0.840 & 0.857 \\
\hline \multicolumn{4}{|c|}{ Площадка, занимаемая одной молекулой $\omega$, нм $^{2}$} \\
\hline & 3.06 & 3.22 & 3.25 \\
\hline
\end{tabular}

$\mathrm{R}^{2}-$ коэффициент детерминации

Из данных табл. 6 следует, что модель Ленгмюра (рис. 14 б) лучше (коэффициенты детерминации близки к единице) описывает изотермы адсорбции МО. Так же, как и в случае кислотного оранжевого красителя, индикатор метиловый оранжевый подтверждает однородность поверхности образца.

Из данных табл. 6 следует, что константа уравнения Ленгмюра $K_{L}$ уменьшается в ряду образцов ПМДН-1, ПМДН-3, ПМДН-2. При этом значения адсорбционной ёмкости монослоя $a_{m}$ для всех образцов практически совпадают (табл. 6). Константа адсорбционного равновесия в уравнении Ленгмюра характеризует энергию взаимодействия адсорбата с адсорбентом. Чем сильнее это взаимодействие, тем больше значение константы адсорбционного равновесия. Следовательно, энергия взаимодействия МО с поверхностью сорбента уменьшается при обработке ПМДН ортофосфорной кислотой, но количество адсорбированного вещества на 1 г сорбента остается постоянным для всех трех образцов. Это может быть связано с тем, что МО является амфотерным соединением и может вступать во взаимодействия как с кислотными, так и с основными группами поверхности. Разница в константах уравне- 
ния Ленгмюра $K_{L}$ может объясняться изменением энергии взаимодействия индикатора за счет ионогенных групп с поверхностью ПМДН.

Обработка кислотой ПМДН приводит к переводу кислотных групп в Нформу, что способствует увеличению общей электроотрицательности поверхности сорбента и уменьшению адсорбции молекул МО с кислотными группами вследствие отталкивания отрицательно заряженных сульфогрупп индикатора и кислотных групп ПМДН. В то же время, обработка кислотой ПМДН приводит к протонированию основных групп сорбента и увеличению взаимодействия кислотных групп MO с основными группами ПМДН.

\section{Заключение}

Определена удельная поверхность пористого микродисперсного детонационного наноалмаза и показано, что обработка его кислотами или щелочами не влияет на структурные характеристики сорбента. Методом кислотно-основного титрования и титрования по методу Боэма оценено количество кислотных и основных групп на поверхности ПМДН. Разработаны методики обработки ПМДН кислотами и щелочами, позволяющие в значительной степени изменять и стабилизировать его химию поверхности и адсорбционные свойства. В статическом режиме измерены изотермы адсорбции сорбатов, обладающих свойствами кислот, оснований и амфотерных соединений. С использованием зависимостей типа уравнений Фрейндлиха и Ленгмюра исследована однородность поверхности ПМДН. Показано, что обработка исходного образца ПМДН кислотой или основанием приводит к уменьшению адсорбции кислотных и основных красителей, что может быть связано с удалением примесей металлов с поверхности ПМДН, с которыми могли бы взаимодействовать кислотные и основные соединения.

\section{Список литературы}

1. Thurman E.M., Mills M.S. Solid-Phase Extraction: Principles and Practice. John Wiley \& Sons Inc. New York. 1998. 372 p.

2. Handbook Of Solid Phase Microextraction. Edited by:Janusz Pawliszyn. Elsevier. 2012. $478 \mathrm{p}$.

3. Рычкова С.А., Ланин С.Н., Шаталов И.А., Востров И.А. // Сорбционные и хроматографические прочессы. 2014. Т. 14. № 3. C. $397-405$.

4. Ланин С.Н., Рычкова С.А., Виноградов А.Е., Вирясов М.Б. и др.. // Сорбиионные и хроматографические процессы. 2015. Т. 15. № 2. C. 179-195.

5. Lanin S.N., Nikitin Yu.S. // Talanta. 1989. Vol. 36. No 5. pp. 573-579. doi:10.1016/0039-9140(89)80126-2.

6. Долматов В.Ю. // Успехи химии. 2001. Т. 70. С. 687.

7. Nesterenko P.N., Haddad P.R. // Anal. Bioanal. Chem. 2010. Vol. 396. pp. 205. doi: 10.1007/s00216-009-3219-5.
8. Peristyy A.A., Fedyanina O.N., Paull B., Nesterenko P.N. // J. Chromatogr. A. 2014. Vol. $1357 . \quad$ pp. $68 . \quad$ doi: 10.1016/j.chroma.2014.06.044.

9. Кулакова И.И. //Физика твердого тела. 2004. Т. 46. Вып. 4. С. 621-628. doi: 10.1134/1.1711440.

10. Lanin S.N., Nikitin Yu.S. // J. Chromatogr. A. 1991. Vol. 537. pp. 33-49. doi: 10.1016/S0021-9673(01)88884-1.

11. Киселев А.В. Межмолекулярные взаимодействия в адсорбции и хроматогарфии. М. Высшая школа. 1986. 360 с.

12. Saini G., Wiest L.A., Herbert D. // J. Chromatogr. A. 2009. Vol. 1216. pp. 3587. doi: 10.1016/j.chroma.2008.11.102.

13. Паркаева С.А., Белякова Л.Д., Ларионов О.Г. // Сорбиионные и хроматографические проиессы. 2010. Т. 10. № 2. С. 283-292.

14. Saini G., Jensen D.S., Wiest L.A. // Anal. Chem. 2010. Vol. 82. pp. 4448. doi: 10.1021/ac1002068. 
15. Федянина О.Н., Нестеренко П.Н. // Журнал физической химии. 2011. Т. 85. C. 1902.

16. Nesterenko P.N., Fedyanina O.N., Volgin Yu.V. // Analyst. 2007. Vol. 132. pp. 403. doi: 10.1039/B702272G.

17. Nesterenko P. N., Fedyanina O.N. // J. Chromatogr. A. 2010. Vol. 1217. pp. 498. doi: 10.1016/j.chroma.2009.11.070.

18. Ланин С.Н., Рычкова С.А., Виноградов А.Е., Ланина К.С. и др. // Известия AH. Ceрия химическая. 2016. № 1. С. 110-119.

19. Lanin S.N., Rychkova S.A., Vinogradov A.E., Lanina K.S. et al. // Diamond and Related Materials. 2016. Vol. 64. pp. 49-56. doi:10.1016/j.diamond.2016.01.005.

20. Ланин С.Н., Банных А.А., Ковалева Н.В. // Журн. физ. химии. 2013. Т. 87. C. 1559 .

\section{References}

1. Thurman E.M., Mills M.S. Solid-Phase Extraction: Principles and Practiceб John Wiley \& Sons Inc. New York, 1998, 372 p.

2. Handbook Of Solid Phase Microextraction. Edited by:Janusz Pawliszyn, Elsevier, 2012, 478 p.

3. Rychkova S.A., Lanin S.N., Shatalov I.A., Vostrov I.A., Sorbtsionnye $i$ khromatograficheskie protsessy,2014, Vol. 14, No 3, pp. $397-$ 405.

4. Lanin S.N., Rychkova S.A., Vinogradov A.E., Viryasov M.B. et al., Sorbtsionnye $i$ khromatograficheskie protsessy, 2015, Vol. 15, No 2, pp. 179-195.

5. Lanin S.N., Nikitin Yu.S., Talanta, 1989, Vol. 36, No 5, pp. 573-579. doi:10.1016/00399140(89)80126-2.

6. Dolmatov V.Yu., Russian Chemical Reviews, 2001, Vol. 70, pp. 607-626. doi:10.1070/RC2001v070n07ABEH000665.

7. Nesterenko P.N., Haddad P.R., Anal. Bioanal. Chem., 2010, Vol. 396, pp. 205. doi: 10.1007/s00216-009-3219-5.

8. Peristyy A.A., Fedyanina O.N., Paull B., Nesterenko P.N., J. Chromatogr. A, 2014, Vol. 1357, pp. $68 . \quad$ doi: 10.1016/j.chroma.2014.06.044.

9. Kulakova I.I., Physics of the Solid State, 2004, Vol. 46, No 4, pp. 636-643. doi: 10.1134/1.1711440.
21. Золотов Ю.А. Задачи и вопросы по аналитической химии. М. Высшая школа. $2002.410 \mathrm{c}$.

22. Вячеславов А.С., Померанцева Е.А. Измерение площади поверхности и пористости методом капиллярной конденсации азота. Московский государственный университет им. М.В.Ломоносова. Метод. разраб. Москва. 2006. 55 с

23. Peristyy A.A., Paull B., Nesterenko P.N. // Adsorption. 2016. Vol. 22. pp. 371-383. doi: 10.1007/s10450-016-9786-9.

24. Mitev D.P., Townsend A.T., Paull B., Nesterenko P.N. // Diamond and Related Materials. 2014. Vol. 48. pp. 37-46.

25. Хмельницкий Р.А. Физическая и коллоидная химия. М. Высшая школа. 1988. 400 c.

10. Lanin S.N., Nikitin Yu.S., J. Chromatogr. $A$, 1991, Vol. 537, pp. 33-49. doi: 10.1016/S0021-9673(01)88884-1.

11. Kiselev A.V. Intermolecular Interactions in Adsorption and Chromatography [in Russian], M., Vyssh. Shkola, 1986, 360 p.

12. Saini G., Wiest L.A., Herbert D., J. Chromatogr. A, 2009, Vol. 1216, pp. 3587. doi: 10.1016/j.chroma.2008.11.102.

13. Parkaeva S.A., Belyakova L.D., Larionov O.G., Sorbtsionnye $i$ khromatograficheskie protsessy, 2010, Vol. 10, No 2, pp. 283-292.

14. Saini G., Jensen D.S., Wiest L.A., Anal. Chem., 2010, Vol. 82, pp. 4448. doi: 10.1021/ac1002068.

15. Fedyanina O.N., Nesterenko P.N., Russ. J. Phys. Chem., 2011, Vol. 85, pp. 1773. doi: 10.1134/S0036024411100062.

16. Nesterenko P.N., Fedyanina O.N., Volgin Yu.V., Analyst, 2007, Vol. 132, pp. 403. doi: 10.1039/B702272G.

17. Nesterenko P. N., Fedyanina O.N., J. Chromatogr. A, 2010, Vol. 1217, pp. 498. doi: 10.1016/j.chroma.2009.11.070.

18. Lanin S.N., Rychkova S.A., Vinogradov A.E., Lanina K.S. et al., Russian Chemical Bulletin. International Edition, 2016, Vol. 65, No 1, pp. 110-119. doi:10.1007/s11172-016-12728.

19. Lanin S.N., Rychkova S.A., Vinogradov A.E., Lanina K.S. et al., Diamond and Related 
Materials, 2016, Vol. 64, pp. 49-56. doi:10.1016/j.diamond.2016.01.005.

20. Lanin S.N., Bannykh A.A., Kovaleva N.V., Russian Journal of Physical Chemistry A, 2013, Vol. 87, pp. 1550-1555. doi:10.1134/S0036024413090124.

21. Zolotov Yu.A., Dorokhova E.N., Fadeev V.I. et al., Osnovy analiticheskoi khimii. V 2-kh kn. Kn. 1. Obshchie voprosy. Metody razdeleniya (Fundamentals of Analytical Chemistry. In two books. Book 1. General Questions. Separation Methods), M., Vyssh. Shkola, 2002, 351 p.

22. Vyacheslavov A.S., Pomerantseva E.A. Measurement of surface area and porosity by capillary condensation of nitrogen. [in Russian] Moscow State University. M., 2006, 55 p.

23. Peristyy A.A., Paull B., Nesterenko P.N., Adsorption, 2016, Vol. 22, pp. 371-383. doi: 10.1007/s10450-016-9786-9.

24. Mitev D.P., Townsend A.T., Paull B., Nesterenko P.N., Diamond and Related Materials, 2014, Vol. 48, pp. 37-46. doi: 10.1016/j.diamond.2014.06.007.

25. Khmelnitsky R.A. Physical and Colloid Chemistry. [in Russian] Moscow Vyssh. Shkola. $1988.400 \mathrm{p}$.
Ланин Сергей Николаевич - д.х.н., проф., зав. лабораторией адсорбции и хроматографии, Московский государственный университет имени М.В. Ломоносова, Москва.

Рычкова Светлана Александровна - аспирант кафедры физической химии, Московский государственный университет имени М.В. Ломоносова, Москва

Виноградов Артем Евгеньевич к.ф.-м.н., научный сотрудник лаборатории адсорбции и хроматографии, Московский государственный университет имени М.В. Ломоносова, Москва.

Вирясов Михаил Борисович - к.Х.Н., ведущий научный сотрудник лаборатории адсорбции и хроматографии, Московский государственный университет имени М.В. Ломоносова, Москва.

Власенко Елена Владимировна - к.х.н., научный сотрудник лаборатории адсорбции и хроматографии, Московский государственный университет имени М.В. Ломоносова, Москва.

Ланина Ксения Сергеевна - к.х.н., младший научный сотрудник лаборатории адсорбции и хроматографии, Московский государственный университет имени М.В. Ломоносова, Москва.

Нестеренко Павел Николаевич - д.х.н., научный сотрудник лаборатории адсорбции и хроматографии, Московский государственный университет имени М.В. Ломоносова, Москва.

Хохлова Татьяна Дмитриевна - д.х.н., ведущий научный сотрудник лаборатории адсорбции и хроматографии, Московский государственный университет имени М.В. Ломоносова, Москва.
Lanin Sergey N. - Dr. Sci., professor, head of the laboratory of adsorption and chromatography Moscow State University, Moscow, e-mail: snlanin@phys.chem.msu.ru

Rychkova Svetlana A. - post-graduate student of department of Physical Chemistry, Moscow State University, Moscow, e-mail: svetlanrychkov@yandex.ru

Vinogradov Artem E. - Ph. D., researcher of the laboratory of adsorption and chromatography Moscow State University, Moscow.

Viryasov Mikhail B. - Ph. D., leading researcher of the laboratory of adsorption and chromatography Moscow State University, Moscow.

Vlasenko Elena V. - Ph. D., researcher of the laboratory of adsorption and chromatography Moscow State University, Moscow.

Lanina Kseniya S. - Ph. D., researcher of the laboratory of adsorption and chromatography Moscow State University, Moscow.

Nesterenko Pavel N. - Dr. Sci., researcher of the laboratory of adsorption and chromatography Moscow State University, Moscow.

Khokhlova Tatyana D. - Dr. Sci., leading researcher of the laboratory of adsorption and chromatography Moscow State University, Moscow. 